\title{
Differential diagnosis of classical Bartter syndrome and Gitelman syndrome: Do we need genetic analysis?
}

\author{
Sercin GUVEN ${ }^{1}$ (D), Ibrahim GOKCE ${ }^{1}$ D , Ceren ALAVANDA ${ }^{2}$ (D), Neslihan CICEK ${ }^{1}$ (D), Ece Bodur DEMIRCI ${ }^{1}$ (D), Mehtap SAK ${ }^{1}$ (D),

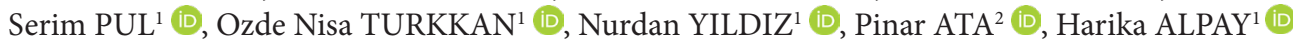 \\ ${ }^{1}$ Division of Pediatric Nephrology, Department of Pediatrics, School of Medicine, Marmara University Hospital, Pendik, Istanbul, Turkey. \\ ${ }^{2}$ Department of Medical Genetics, School of Medicine, Marmara University, Marmara, Istanbul, Turkey. \\ Corresponding Author: Sercin GUVEN \\ E-mail: sercindr@yahoo.com \\ Submitted: 10.03.2021 Accepted: 27.06.2021
}

\begin{abstract}
Objective: Classical Bartter syndrome (cBS) and Gitelman syndrome (GS) are genotypically distinct, but there is a phenotypic overlap among these two diseases, which can complicate the accurate diagnosis without genetic analysis. This study aimed to evaluate the correlation between clinical and genetic diagnoses among patients who have genetically defined cBS and GS.

Patients and Methods: The study included 18 patients with homozygous/compound heterozygous CLCNKB (NM_000085) (n:10/18) and SLC12A3 (NM_000339) (n:8/18) mutations. Biochemical, clinical and radiological data were collected at presentation and at the last visit.

Results: In cBS group age at diagnosis, median plasma potassium and chloride concentrations were significantly lower and median plasma $\mathrm{HCO} 3$ and blood $\mathrm{pH}$ values were significantly higher. Patients with GS had significantly lower median plasma magnesium concentrations and urinary calcium/creatinine ratio. One child with GS had normocalciuria, two children with cBS had hypocalciuria and hypomagnesemia. Low estimated glomerular filtration rate (eGFR) $(\mathrm{ml} / \mathrm{dk} / 1.73 \mathrm{~m} 2)$ and growth failure were more evident in cBS group. In patients with $\mathrm{CBS}$, nine different CLCNKB gene mutations were detected, five of them were novel. Novel mutations were: one nonsense (c.66G>A, p.Trp22*), one missense (c.499G>A, p.Gly167Ser) and three splice-site (c.867-2delA; c.499-2insG; c.1930$2 \mathrm{~A}>\mathrm{C}$ ) mutations. In patients with GS, six different SLC12A3 gene mutations were found.

Conclusions: It may not always be possible to clinically distinguish cBS from GS. We suggest to perform a genotypic classification if genetic analysis is possible.

Keywords: Bartter syndrome, Gitelman syndrome, Kidney tubuler disease, Hypokalemic metabolic alkalosis
\end{abstract}

\section{INTRODUCTION}

Bartter (BS) and Gitelman syndromes (GS) are autosomal recessive inherited salt-losing tubulopathies, characterized by hypokalemic hypochloremic metabolic alkalosis and normal blood pressure in the context of elevated renin and aldosterone levels [1]. Clinically, these tubulopathies are often categorized into 3 major subgroups: antenatal BS (aBS), classical BS (cBS) and GS. BS type-3 also known as $\mathrm{CBS}$ is caused by loss of function mutations in $C L C N K B$ gene. $C L C N K B$ gene encodes a chloride channel protein $\mathrm{CIC}-\mathrm{Kb}$, expressed in the thick ascending limp (TAL) of Henle's loop, the distal convoluted tubule (DCT), the connecting tubule and the collecting duct [1-3]. $\mathrm{CIC}-\mathrm{Kb}$ has a role in the reabsorption of sodium chloride in the TAL and the loss of function mutations in CLCNKB gene cause electrolyte abnormalities called 'loop phenotype'. The use of loop diuretics results in the same electrolyte abnormalities [2,3]. GS was initially thought to be a subtype of BS but advances in molecular genetics showed that it was a separate entity. GS is caused by loss of function mutations in the gene SLC12A3, encoding thiazidesenstitive $\mathrm{NaCl}$ cotransporter called NCCT of the DCT [3]. The NCCT is responsible for the sodium reabsorption in the DCT and like with loop dysfunction, impaired sodium reabsorption in the DCT causes characteristic electrolyte abnormalities, called 'DCT' phenotype [3].

Classical BS and GS share some metabolic abnormalities such as hypochloremic hypokalemic metabolic alkalosis. Clinical and metabolic findings like hypercalciuria, normomagnesemia,

How to cite this article: Guven S, Gokce I, Alavanda C, et al. Differential diagnosis of classical Bartter syndrome and Gitelman syndrome: Do we need a genetic analysis? Marmara Med J 2021; 34(3):254-259. doi: 10.5472/marumj.1012351 
early onset at younger age or severity of the disease are used to distinguish cBS from GS. In most cases, the correct diagnosis can be made without genetic analysis. However, it may not always allow distinction between them. Because hypercalciuria is not present always in all cases of cBS and some patients with cBS have hypomagnesemia, which is a typical feature of GS. Also, neither hypocalciuria nor hypomagnesemia are consistent findings in GS $[4,5]$. This study aimed to clarify clinical and laboratory findings among patients with genetically defined cBS and GS and evaluate the correlation between clinical diagnoses and genetic diagnoses.

\section{PATIENTS and METHODS}

\section{Patients and biochemical analysis}

The study included eighteen patients with homozygous or compound heterozygous CLCNKB (n:10/18) and SLC12A3 (n:8/18) mutations presenting to the pediatric nephrology division of a university hospital. Biochemical, clinical and radiological data were collected at presentation and at the last clinic follow-up visit. Hypomagnesemia was defined as a serum magnesium concentration less than $1.7 \mathrm{mg} / \mathrm{dl}$, hypokalaemia was defined as a serum concentration less than $3.5 \mathrm{mEq} / \mathrm{L}$, hypochloremia was defined as a serum chloride concentration less than $98 \mathrm{mg} / \mathrm{dl}$. Normocalciuria was defined with the normal ranges for the patient's age. Estimated glomerular filtration rate (eGFR) was calculated using the modified Schwartz formula, with a k-value of 0.413. Body height percentiles of patients were recorded at the presentation and at the last follow-up visit. Growth failure was defined as a height persentile less than 3. Kidney ultrasound imaging was performed at presentation and in the follow-up of all children.

\section{Molecular Genetics studies}

After detailed pedigree analyses and written informed consents were obtained, all patients' and their parents' total genomic DNA was extracted from peripheral blood using QIAamp DNA Mini Kit (Qiagen, Hilden, Germany). For all patients sequencing of CLCNKB (NM_000085) and SLC12A3 genes (NM_000339) were performed using two different methods: Sanger sequencing and Next-Generation Sequencing (NGS). All samples were first analyzed by NGS and after detection of sequence changes, confirmation of them were performed using Sanger sequencing with targeted sequencing for those already detected mutations/variations. The Nephropathies Solution (NES) kit by Sophia Genetics (Switzerland) was used for NGS (Illumina Nextseq 500) and single nucleotide polymorphisms (SNPs) and copy number variations (CNVs) were analyzed through Sophia-DDM-v4 platform [ ]. For both of these genes, specific primers were designed for all exons and exon-intron junctions and Sanger sequencing was performed via $A B I$ PRISM 3130xl Genetic Analyzer (AppliedBiosystems, Foster City, CA, USA). SNPs were analyzed with Chromas software version 2.4.1. Variants with minor allele frequency (MAF) $<1 \%$ according to population studies [ESP, ExAC, 1000 Genome $(1000 \mathrm{G})$, and Genome aggregation database (gnomAD)] were filtered and retained variants were searched in Human Gene Mutation Database (HGMD), Clinvar and Varsome Databases. Pathogenicity scores were predicted using Mutation taster, Provean, Polyphen, Human Splicing Finder (HSF) and Sorting Intolerant From Tolerant (SIFT) in - silico tools.

\section{Statistical analysis}

All data were analyzed using the Statistical Packages for the Social Sciences (SPSS Inc., Chicago, IL, USA) 21.0 package. A One Sample Kolmogorov-Smirnov test was used to determine the normality of data. Results were expressed as mean with standard deviation (mean $\pm \mathrm{SD}$ ) in case of normal distribution and median (range) in case of non-normal distribution. Differences between categorical data were evaluated using t-test and Mann-Whitney non-parametric U test in normal distribution and non-normal distribution, respectively. A p-value of less than 0.05 was considered statistically significant.

\section{RESULTS}

Biochemical features and clinical features at presentation and at the last follow-up visit are summarized in Table I. Ten patients presented with cBS and eight patients with GS. Five patients (50\%) with cBS and five patients (62.5\%) with GS were male. Patients with cBS had a significantly lower median age at diagnosis than the patients with GS (11.5 vs. 128 months, respectively). The median follow-up time was 33 months in patients with cBS and 47 months in patients with GS.

Table I. Clinical, demographic and biochemical characteristics of the patients

\begin{tabular}{|l|l|l|l|}
\hline & $\begin{array}{l}\text { Classical Bartter } \\
\text { Syndrome } \\
(\mathrm{n}=10)\end{array}$ & $\begin{array}{l}\text { Gitelman } \\
\text { Syndrome } \\
(\mathrm{n}=8)\end{array}$ & $\mathrm{p}$ \\
\hline Age, months & $11,5(1-76)$ & $128(44-209)$ & $<\mathbf{0 . 0 0 1}$ \\
\hline Female/male, $\mathrm{n}(\%)$ & $5 / 5(50 \%)$ & $3 / 5(60 \%)$ & 0.664 \\
\hline Follow-up, months & $33(3-120)$ & $47(19-174)$ & 0,200 \\
\hline Prematurity, $\mathrm{n}(\%)$ & $3(30 \%)$ & $0(0 \%)$ & 0,090 \\
\hline Blood pH & $7.57(7.40-7.70)$ & $7.44(7.40-7.59)$ & $\mathbf{0 . 0 0 3}$ \\
\hline Blood HCO3 (mEq/L) & $41.1(21.8-51.5)$ & $30.6(27.4-32.4)$ & $\mathbf{0 . 0 1 0}$ \\
\hline Plasma potassium (mEq/L) & $2.2(1.9-3.1)$ & $2.8(2.2-3.7)$ & $\mathbf{0 . 0 0 2}$ \\
\hline Plasma chloride (mg/L) & $85(67-96)$ & $95(88-101)$ & $<\mathbf{0 . 0 0 1}$ \\
\hline Plasma magnessium (mg/dl) & $2.15(1.6-2.7)$ & $1.4(1.30-1.50)$ & $\mathbf{0 . 0 0 1}$ \\
\hline $\begin{array}{l}\text { Urinary calcium/creatinine } \\
\text { ratio (mg/mg) }\end{array}$ & $0.6(0.03-1.9)$ & $0,01(0.01-0.67)$ & $<\mathbf{0 . 0 0 1}$ \\
\hline $\begin{array}{l}\text { eGFR (ml/dk/1.73 m²) } \\
\text { (at presentation) }\end{array}$ & $103(49-172)$ & $137(99-172)$ & $\mathbf{0 . 0 4 3}$ \\
\hline $\begin{array}{l}\text { eGFR (ml/dk/1.73 m²) } \\
\text { (at the last visit) }\end{array}$ & $103(76-192)$ & $112(89-271)$ & 0.410 \\
\hline $\begin{array}{l}\text { Height <3.persentile } \\
\text { (at presentation) }, \mathrm{n}(\%)\end{array}$ & $5(50 \%)$ & $2(25 \%)$ & 0.280 \\
\hline $\begin{array}{l}\text { Height <3.persentile } \\
\text { (at the last visit), } \mathrm{n}(\%)\end{array}$ & $3(30 \%)$ & $1(12.5 \%)$ & 0.370 \\
\hline
\end{tabular}

Values are represented as median (min - max), eGFR, estimated glomerular filtration rate 
Median plasma potassium and chloride concentrations were significantly lower in cBS group (2.2 vs. $2.8 \mathrm{mEq} / \mathrm{L} ; 85$ vs. 95 $\mathrm{mg} / \mathrm{L}$, respectively). Median plasma $\mathrm{HCO} 3$ concentrations and blood $\mathrm{pH}$ values were significantly higher in cBS group (41.1 vs. $30.6 \mathrm{mEq} / \mathrm{L}$; 7.57 vs. 7.44 respectively). Patients with GS had significantly lower median plasma magnesium concentrations (1.40 vs.2.15 mg/dl respectively) and urinary calcium/ creatinine ratio ( 0,01 vs. 0,6 respectively). One child with GS had normocalciuria and two children with cBS had both hypocalciuria and hypomagnesemia at presentation. Median eGFR $\left(\mathrm{ml} / \mathrm{dk} / 1.73 \mathrm{~m}^{2}\right)$ at presentation were significantly lower in cBS patients than patients with GS (103 vs. $137 \mathrm{ml} / \mathrm{dk} / 1.73 \mathrm{~m}^{2}$ respectively). At the last follow-up, patients with $\mathrm{cBS}$ had still lower eGFR (103 vs. $112 \mathrm{ml} / \mathrm{dk} / 1.73 \mathrm{~m}^{2}$ respectively). Growth failure was the most frequent complaint of patients with $\mathrm{cBS}$ and it was more evident in patients with $\mathrm{cBS}$ (50\% at presentation;
$30 \%$ at last follow-up visit). Ultrasonography performed at presentation and in the follow-up showed nephrocalcinosis in only one child with $\mathrm{cBS}$.

Molecular analyses, revealed mutations that are shown in Tables II and III. In ten patients with cBS, nine different CLCNKB(NM_000085) gene mutations were detected (Table II). Five of them were novel mutations. Novel mutations were: one nonsense (c.66G>A, p.Trp22*), one missense (c.499G>A, p.Gly167Ser) and three splice-site (c.867-2delA; c.499-2insG; c.1930-2A >C) mutations. In eight patients with GS, six different SLC12A3 (NM_000339) gene mutations were detected (Table III). Only one patient had compound heterozygous mutation and the majority of mutations caused a frameshift c.237_238dupCC (p.Arg80Profs ${ }^{\star 35)}$ mutation.

Table II. Nine variants with five novel variants (showed in bold) in classical Bartter syndrome-related gene

\begin{tabular}{|c|c|c|c|c|c|c|}
\hline Patients & Gene & Status & Mutation & Position & Type of mutation & Reference \\
\hline B1 & CLCNKB & Homozygous & $\begin{array}{l}\text { c.371C }>\mathrm{T} \\
\text { (p.Prol24Leu) }\end{array}$ & Exon 5 & Missense & Simon et al.,1997 [6] \\
\hline B2 & CLCNKB & Homozygous & $\begin{array}{l}\text { c.371C }>\mathrm{T} \\
\text { (p.Prol24Leu) }\end{array}$ & Exon 5 & Missense & Simon et al., 1997 [6] \\
\hline B3 & CLCNKB & Homozygous & c.867-2delA & Intron 8 & Splice-site & This study \\
\hline B4 & CLCNKB & Homozygous & Exon 2-20 deletion & Exon 2-20 & Gross deletion & Simon et al.,1997[6] \\
\hline B5 & CLCNKB & Homozygous & c.499-2insG & Intron 4 & Splice-site & This study \\
\hline B6 & CLCNKB & Homozygous & $\begin{array}{l}\text { c. } 910 \mathrm{C}>\mathrm{T} \\
\left(\mathrm{p} \cdot \operatorname{Arg} 304^{*}\right) \\
\end{array}$ & Exon 10 & Nonsense & Messa et al., 2020[7] \\
\hline B7 & CLCNKB & Homozygous & $\begin{array}{l}\text { c. } 910 \mathrm{C}>\mathrm{T} \\
\left(\mathrm{p} . \operatorname{Arg} 304^{*}\right) \\
\end{array}$ & Exon 10 & Nonsense & Messa et al., 2020[7] \\
\hline B8 & CLCNKB & Homozygous & c. $1930-2 \mathrm{~A}>\mathrm{C}$ & Intron 18 & Splice-site & This study \\
\hline B9 & CLCNKB & Homozygous & \begin{tabular}{|l} 
c.499G $>$ A \\
(p.Gly167Ser)
\end{tabular} & Exon 5 & Missense & This study \\
\hline $\mathrm{B} 10$ & CLCNKB & Compound heterozygous & $\begin{array}{l}\text { c.66G >A (p.Trp22*) } \\
\text { c.865G }>\text { C (p.Gly289Arg) }\end{array}$ & $\begin{array}{l}\text { Exon } 2 \\
\text { Exon } 9\end{array}$ & $\begin{array}{l}\text { Nonsense } \\
\text { Missense }\end{array}$ & $\begin{array}{l}\text { This study and } \\
\text { Sahbani et al.,2020[8] }\end{array}$ \\
\hline
\end{tabular}

Table III. Six variants in Gitelman syndrome-related genes

\begin{tabular}{|c|c|c|c|c|c|c|}
\hline Patients & Gene & Status & Mutation & Location & Type of mutation & Reference \\
\hline G1 & SLC12A3 & Homozygous & c. $1180+1 \mathrm{G}>\mathrm{T}$ & IVS 9 & Splice-site & Coto et al., 2004[9] \\
\hline G2 & SLC12A3 & $\begin{array}{l}\text { Compound } \\
\text { heterozygous }\end{array}$ & $\begin{array}{l}\text { c.237_238dupCC } \\
\left.\text { (p.Arg80Profs }{ }^{\star} 35\right) \\
\text { c.514T>C (p.Trp172Arg) }\end{array}$ & $\begin{array}{l}\text { Exon } 1 \\
\text { Exon } 4\end{array}$ & $\begin{array}{l}\text { Frameshift } \\
\text { Missense }\end{array}$ & $\begin{array}{l}\text { Mastroianni et al., 1996[10] } \\
\text { Syren et al., 2002[11] }\end{array}$ \\
\hline G3 & SLC12A3 & Homozygous & c.625C >T (p.Arg209Trp) & Exon 5 & Missense & Simon et al., 1996[3] \\
\hline G4 & SLC12A3 & Homozygous & c.1175C >T (p.Thr392Ile) & Exon 9 & Missense & Colussi et al., 2007[12] \\
\hline G5 & SLC12A3 & Homozygous & $\begin{array}{l}\text { c.237_238dupCC } \\
\left.\text { (p.Arg80Profs }{ }^{\star} 35\right)\end{array}$ & Exon 4 & Frameshift & Mastroianni et al., 1996[10] \\
\hline G6 & SLC12A3 & Homozygous & $\begin{array}{l}\text { c.237_238dupCC } \\
\left.\text { (p.Arg80Profs }{ }^{\star} 35\right) \\
\end{array}$ & Exon 4 & Frameshift & Mastroianni et al., 1996[10] \\
\hline G7 & SLC12A3 & Homozygous & $\begin{array}{l}\text { c.237_238dupCC } \\
\left(\text { p.Arg80Profs }{ }^{*} 35\right)\end{array}$ & Exon 4 & Frameshift & Mastroianni et al., 1996[10] \\
\hline G8 & SLC12A3 & Homozygous & c.1964G>A (p.Arg655His) & Exon 16 & Missense & Simon et al., 1996[3] \\
\hline
\end{tabular}




\section{DISCUSSION}

The present study describes the initial clinical and biochemical characteristics and the genetic findings of the patients with cBS and GS. According to our findings, age at diagnosis, the urinary calcium/creatinine ratio, plasma chlorid, magnesium, bicarbonate levels may be useful markers for differentiating cBS and GS. Although, cBS and GS are genotypically distinct, there is considerable overlap in clinical presentation. cBS may sometimes mimic GS and some patients with $\mathrm{cBS}$ appear to have a phenotypic switch [13]. cBS is generally considered to be a disorder of TAL, whereas GS is a disorder of DCT. Initially, some cBS patients present with loop (or BS) phenotype but later they revert to a DCT (or Gitelman like) phenotype [14]. The expression of CLCNKB also in DCT may explain the phenotypic similarity of $\mathrm{CBS}$ and GS.

It is known that $\mathrm{cBS}$ often presents clinically before the age of two [15]. In this study, the age at diagnosis differed significantly between two diseases. Only one patient with cBS was diagnosed after the age of two years, whereas the youngest patient in GS group was 44 months old at the time of diagnosis.

Hypochloremia, hypokalemia and metabolic alkolosis are hallmarks of cBS. In our study, serum chloride and potassium levels were significantly lower and bicarbonate levels were higher in patients with cBS than GS as expected.

Hypercalciuria and normomagnesemia are used to distinguish cBS from GS. Hypercalciuria and nephrocalcinosis which are very important risk factors for chronic kidney disease progression, are less commonly seen in patients with cBS than $\mathrm{aBS}$ and not an expected finding in GS. Impaired salt reabsorption in the TAL leads to an impaired paracellular cation uptake, mostly manifesting as hypercalciuria as with $C L C N K B$ mutations [1]. In contrast to loop dysfunction, impaired salt reabsorption in the DCT paracellular calcium reabsorption in the TAL is unaffected and patients typically have hypocalciuria due to a compensatory increase in salt and calcium reabsorption in the proximal tubule as with $S L C 12 A 3$ mutations [1]. Hypomagnesemia is present in $20-52 \%$ of patients with BS and this is caused by magnesium wasting [16]. Among our patients, hypercalciuria was found in six of ten patients with cBS. However, some patients with cBS may have hypomagnesemia and hypocalciuria [14,17-19]. Zelikovic et al., had reported that four patients in the 12 family members with CLCKNB mutations had concominant hypomagnesemia and hypocalciuria [20]. In our study, two children with cBS $(B 4, B 7)$ had both hypocalciuria and hypomagnesemia at presentation. Patient B4 had a gross deletion (Exon 2-20 deletion) and patient B7 had a homozygous nonsense mutation (p.Arg304*) in exon 10 of CLCNKB gene. But we did not observe hypomagnesemia and hypocalciuria in another patient (B6) with the same mutation as patient B7. Recently, Ring et al. and Kamel et al., also reported that patients with GS may have normocalciuria $[4,5]$.

In the present study, patients with GS had a significantly lower median plasma magnesium concentrations and urinary calcium/ creatinine ratio. But similar to the above mentioned studies, one child with GS (G5) had normocalciuria. Patient G5 had a homozygous frameshift mutation (p.Arg80Profs $\left.{ }^{*} 35\right)$ in exon 4 of SLC12A3 gene. However, our other patient (G6) with the same mutation had hypocalciuria. It is still unclear why the same genetic defect causes different clinical outcomes but Zelikovic et al., hypothesized that a modifying genetic effect on any one of channels participating in $\mathrm{Cl}^{-}$transport in the TAL and the DCT may influence the disease phenotype [20]. Genetic analysis is pivotal for an accurate diagnosis in such patients.

Impaired GFR is observed more commonly in patents with BS than GS. It has been reported that $25 \%$ of patients with cBS suffer from CKD [15,21-24]. In our study, four patients with cBS had impaired GFR at admission, whereas only two patients had CKD stage-II at the end of follow-up. However, all patients with GS had an eGFR greater than $90 \mathrm{ml} / \mathrm{dk} / 1.73 \mathrm{~m}^{2}$ at admission and at the end of follow-up period. The mechanism of CKD development is probably multifactorial. Nephrocalcinosis, chronic hypokalaemia, prematurity, long-term treatment with NSAIDs and damaging effect of elevated aldosterone levels on podocytes are some of the possibilities for CKD development in patients with BS and GS.

One recent study covering 30 patients with cBS detected no genotype-phenotype association [25], whereas Seys et al., reported an association between complete loss of function (CL/ CL) mutations of CLCNKB mutations and severe phenotypes [21]. Although, we did not demonstrate by functional analysis, there was only one large deletion (Exon 2-20 deletion, patient B4) in our cohort that could be predicted to cause complete loss of function. This patient had the lowest eGFR at presentation. Although, previous studies from different countries $[18,21,26]$ reported that whole gene deletion was the most common mutation in $C L C N K B$ gene, in our cohort only one patient had this mutation. When our patients were evaluated in terms of genotype-phenotype correlation, no significant correlation was found even among patients harboring the same mutation.

The major limitations of our study were the low number of our patients and the relatively short period of follow up. Long term follow up of a larger number of patients could allow us to identify a significant difference in growth between these two study groups. Nonethless, the strength of our study is that the diagnosis of our patients were confirmed by very detailed genetic analyses. Prospective studies with larger number of patients, longer follow-up time and genetic confirmation will allow better demonstration of the genotype-phenotype correlation.

\section{Conclusions}

According to our findings, age at diagnosis, plasma chlorid, magnesium, bicarbonate levels and the urinary calcium/ creatinine ratio may be useful markers for differentiating cBS and GS. But, in some cases, cBS cannot be distinguished clinically from GS, especially in patients with overlapping features. For this reason we suggest to perform a gene-based classification especially in countries where genetic analysis is possible.

Compliance with the Ethical Standards The study was approved by the Ethics Committee of Marmara University, School of Medicine (Protocol number: 09.2021.157 ). The 
study protocol was described to all patients and their parents and written informed consent was obtained from all individual participants older than 18 years of age and from the parents of all children included in the study.

Financial Support: The authors have no relevant financial information to disclose.

Conflict of Interest: The authors have no potential conflicts to disclose.

Authors' Contrubition: S.G.,I.G.,C.A. Concept and Design. I.G., H.A., P.A.,N.Y. Supervision. S.G., C.A., E.D.B., M.S., S.P., O.N.T. Materials. S.G.,C.A., E.D.B., M.S., S.P., O.N.T., P.A. Data Collection and Processing. S.G., N.C. Analysis and Interpretation. S.G., I.G. Literature Search. S.G., N.C.,S.G., I.G., N.C., C.A. S.G., N.C. Writing the article. I.G., P.A., H.A. Critical review. All authors approved the final version of the article.

\section{REFERENCES}

[1] Besouw MTP, Kleta R, Bockenhauer D. Bartter and Gitelman syndromes: Questions of class. Pediatr Nephrol 2020 ;35:181524. https://doi.org/10.1007/s00467.019.04371-y

[2] Seyberth HW. Pathophysiology and clinical presentations of salt-losing tubulopathies. Pediatr Nephrol 2016; 31:407-18 https://doi.org/10.1007/s00467.015.3143-1

[3] Simon DB, Nelson-Williams C, Bia MJ. et al. Gitelman's variant of Bartter's syndrome, inherited hypokalaemic alkalosis, is caused by mutations in the thiazide-sensitive Na-Cl cotransporter. Nat Genet 1996; 12: 24-30. https://doi. org/10.1038/ng0196-24

[4] Kamel KS, Harvey E, Douek K, Parmar MS, Halperin ML. Studies on the pathogenesis of hypokalemia in Gitelman's syndrome: Role of bicarbonaturia and hypomagnesemia. Am J Nephrol 1998;18:42-9.

[5] Ring T, Knoers N, Oh MS, Halperin ML. Reevaluation of the criteria for the clinical diagnosis of Gitelman syndrome. Pediatr Nephrol 2002;17:612-16. https://doi.org/10.1159/000013303

[6] Simon DB, Bindra RS, Mansfield TA. et al. Mutations in the chloride channel gene, CLCNKB, cause Bartter's syndrome type III. Nat Genet $1997 ; 17: 171-8$.

[7] Messa HL, de Oliveira Achili Ferreira JC, Andreia RangelSantos, Vaisbich MH. Genetic spectrum of Brazilian suspected Bartter Syndrome Patients. https://doi.org/10.21203/ rs.3.rs-35560/v1(preprint)

[8] Sahbani D, Strumbo B, Tedeschi S, et al. Functional study of novel Bartter's Syndrome mutations in $\mathrm{ClC}-\mathrm{Kb}$ and rescue by the accessory subunit Barttin toward personalized medicine. Front Pharmacol 2020 ;11:327. https://doi.org/10.3389/ fphar.2020.00327

[9] Coto E, Rodriguez J, Jeck N, et al. A new mutation (intron 9 $+1 \mathrm{G}>\mathrm{T}$ ) in the SLC12A3 gene is linked to Gitelman syndrome in Gypsies. Kidney Int 2004 ;65:25-9. https://doi.org/10.1111/ j.1523-1755.2004.00388.x

[10] Mastroianni N, Bettinelli A, Bianchetti M, et al. Novel molecular variants of the $\mathrm{Na}-\mathrm{Cl}$ cotransporter gene are responsible for Gitelman syndrome. Am J Hum Genet 1996
;59:1019-26. http://www.ncbi.nlm.nih.gov/pmc/articles/ pmc1914834

[11] Syrén ML, Tedeschi S, Cesareo L, et al. Identification of fifteen novel mutations in the SLC12A3 gene encoding the $\mathrm{Na}-\mathrm{Cl} \mathrm{Co}-$ transporter in Italian patients with Gitelman syndrome. Hum Mutat $2002 ; 20: 78$. doi: 10.1002/humu.9045. Erratum in: Hum Mutat $2002 ; 20: 321$ https://doi.org/10.1002/humu.9045

[12] Colussi G, Bettinelli A, Tedeschi S, et al. A thiazide test for the diagnosis of kidney tubular hypokalemic disorders. Clin J Am Soc Nephrol 2007;2:454-60. https://doi.org/10.2215/ cjn.02950906

[13] Zelikovic I. Hypokalaemic salt-losing tubulopathies: an evolving story. Nephrol Dial Transplant 2003;18:1696-700. https://doi.org/10.1093/ndt/gfg249

[14] Jeck N, Konrad M, Peters M, Weber S, Bonzel KE, Seyberth HW. Mutations in the chloride channel gene, CLCNKB,leadingto a mixed Bartter-Gitelman phenotype. Pediatr Res 2000; 48:7548. https://doi.org/10.1203/00006.450.200012000-00009

[15] Peters M, Jeck N, Reinalter S, et al. Clinical presentation of genetically defined patients with hypokalemic salt-losing tubulopathies. Am J Med 2002; 112: 183-90.

[16] Bettinelli A, Bianchetti MG, Girardin E, et al. Use of calcium excretion values to distinguish two forms of primary renal tubular hypokalemic alkalosis: Bartter and Gitelman syndromes. J Pediatr 1992;120: 38-43. https://doi.org/10.1016/ s0022-3476(05)80594-3

[17] Nozu K, Iijima K, Kanda K, et al. The pharmacological characteristics of molecular-based inherited salt-losing tubulopathies. J Clin Endocrinol Metab 2010;95:511-8. https:// doi.org/10.1210/jc.2010-0392

[18] Lee BH, Cho HY, Lee H, et al. Genetic basis of Bartter syndrome in Korea. Nephrol Dial Transplant 2012;27:151621. https://doi.org/10.1093/ndt/gfr475

[19] Vargas-Poussou R, Dahan K, Kahila D, et al. Spectrum of mutations in Gitelman syndrome. J Am Soc Nephrol 2011; 22:693-703. https://doi.org/10.1681/asn.201.009.0907

[20] Zelikovic I, Szargel R, Hawash A, et al. A novel mutation in the chloride channel gene, CLCNKB, as a cause of Gitelman and Bartter syndromes. Kidney Int 2003; 63:24-32. https://doi. org/10.1046/j.1523-1755.2003.00730.x

[21] Seys E, Andrini O, Keck M, et al. Clinical and genetic spectrum of Bartter Syndrome type 3 J Am Soc Nephrol 2017;28:254052. https://doi.org/10.1681/asn.201.610.1057

[22] Bettinelli A, Borsa N, Bellantuono R, et al. Patients with biallelic mutations in the chloride channel gene CLCNKB: longterm management and outcome. Am J Kidney Dis 2007; 49: 91-8 https://doi.org/10.1053/j.ajkd.2006.10.001

[23] Puricelli E, Bettinelli A, Borsa N, et al. Long-term follow-up of patients with Bartter syndrome type I and II. Nephrol Dial Transplant 2010; 25: 2976-81 https://doi.org/10.1093/ndt/ gfq119

[24] Brochard K, Boyer O, Blanchard A, et al. Phenotype-genotype correlation in antenatal and neonatal variants of Bartter syndrome. Nephrol Dial Transplant 2009; 24: 1455-64 https:// doi.org/10.1093/ndt/gfn689 
[25] García Castaño A, Pérez de Nanclares G, Madariaga L, et al. Renal Tube Group: Poor phenotypegenotype association in a large series of patients with Type III Bartter syndrome. PLoS One 2017 ;12:e173581. https //doi: 10.1371/journal. pone. 0173581
[26] Han Y, Lin Y, Sun Q, Wang S, Gao Y, Shao L . Mutation spectrum of Chinese patients with Bartter syndrome. Oncotarget 2017;8:101614-22. https://doi.org/10.18632/ oncotarget. 21355 